
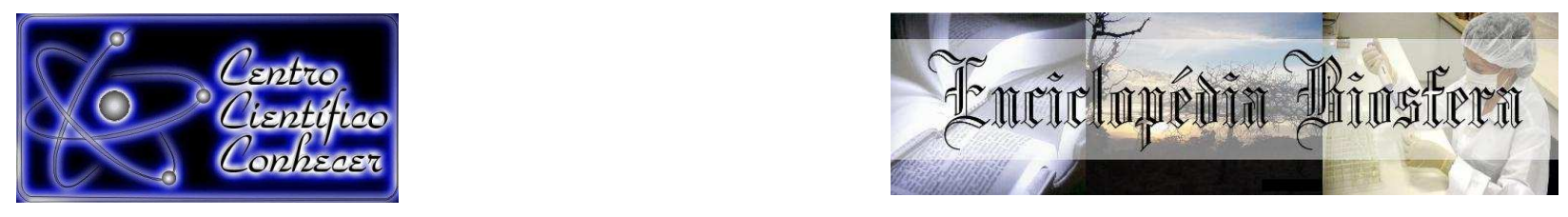

\title{
AVALIAÇÃO DE ATRIBUTOS QUíMICOS DE SOLO SUBMETIDO À APLICAÇÃO DE ÁGUA RESIDUÁRIA DE ABATEDOURO DE AVES
}

Tamiris Uana Tonello ${ }^{1}$, Cláudia Salim Lozano ${ }^{2}$, Marcelo Alessandro Araújo ${ }^{3}$, Edmilson Cesar Bortoletto ${ }^{3}$, Anna Paola Tonello ${ }^{4}$

1 Mestranda, Pós Graduação em Engenharia Agrícola - PGEAGRE - Universidade

Estadual do Oeste do Paraná, Cascavel, Paraná - Brasil;

2 Mestranda, Pós Graduação em Agronomia - DAG - Universidade Estadual de

Maringá, (claulozano93@gmail.com) Maringá, Paraná - Brasil;

3 Professor Doutor do Departamento de Engenharia Agrícola da Universidade

Estadual de Maringá, Cidade Gaúcha, Paraná - Brasil;

4 Doutoranda, Pós Graduação em Agronomia - DAG - Universidade Estadual de Maringá, Maringá, Paraná - Brasil.

Recebido em: 08/04/2016 - Aprovado em: 30/05/2016 - Publicado em: 20/06/2016 DOI: 10.18677/Enciclopedia_Biosfera_2016_011

\section{RESUMO}

Nos últimos anos o Brasil vem ganhando destaque na produção de carne de frango, figurando no cenário mundial como maior exportador e terceiro maior produtor. Este avanço apesar de positivo gera também uma maior produção de resíduos. A destinação correta destes resíduos é um dos grandes desafios ambientais da indústria, tendo como alternativa o uso em áreas agrícolas. Neste sentido, este trabalho teve como objetivo avaliar os possíveis efeitos da aplicação de água residuária de abatedouro de aves (ARAA) nas características químicas de um Latossolo Vermelho Distrófico cultivando capim Mombaça. O experimento foi conduzido em ambiente protegido, utilizando colunas de PVC, localizado no Departamento de Engenharia agrícola da Universidade Estadual de Maringá. O delineamento estatístico utilizado foi inteiramente ao acaso (DIC) com quatro repetições. Os tratamentos constituíram-se de doses de ARAA, (0, 150, 300, 600 e $\left.900 \mathrm{~m}^{3} \mathrm{ha}^{-1}\right)$. Foram coletadas amostras de solo em duas camadas $(0,00-0,25 \mathrm{e}$ 0,25-0,50 m) antes da aplicação de ARAA e ao término do experimento. Avaliouse $\mathrm{o} \mathrm{pH}$, condutividade elétrica e as concentrações de cálcio, magnésio, nitrogênio, fósforo e potássio do solo. Sendo possível observar que a ARAA contribuiu para o aumento do $\mathrm{pH}$ e redução da condutividade elétrica, cálcio e magnésio em ambas as camadas. Houve aumento dos teores de nitrogênio e potássio na camada de 0,25-0,50 m. Além de proporcionar condições favoráveis para absorção de alguns nutrientes pelas plantas. Porém novos estudos com maiores doses e diversos ciclos tornam-se necessários para se ter maior clareza sobre o comportamento da ARAA no solo.

PALAVRAS-CHAVE: efluente, impacto ambiental, reuso. 


\title{
ATTRIBUTES ASSESSMENT CHEMICAL UNDER GROUND WATER APPLICATION WASTEWATER POULTRY SLAUGHTERHOUSE
}

\begin{abstract}
In recent years Brazil has been gaining attention in the production of chicken meat, appearing on the world stage as the largest exporter and third largest producer. This advance despite positive also generates greater waste production. The proper disposal of this waste is one of the major environmental challenges facing the industry, and as an alternative use in agricultural areas. Thus, this study aimed to evaluate evaluate the possible effects of the application of poultry slaughterhouse wastewater (ARAA) on the chemical characteristics of a Dystrophic Red Latosol cultivated with Mombasa grass. The experiment was conducted in a greenhouse located in the Departamento de Engenharia Agrícola of the Universidade Estadual de Maringá, using PVC columns. The statistical design was completely randomized (CRD) with four replications. The treatments consisted of ARAA doses, $(0,150,300$, 600 and $\left.900 \mathrm{~m}^{3} \mathrm{ha}^{-1}\right)$. Soil samples were collected in two layers $(0.0-0.25$ and $0.25-$ $0.50 \mathrm{~m}$ ) before applying ARAA and at the end of the experiment. It was evaluated the $\mathrm{pH}$, electrical conductivity and concentrations of calcium, magnesium, nitrogen, phosphorus and potassium of the soil. It was possible to verify that ARAA contributed to increasing the $\mathrm{pH}$ of the soil and reduction of electrical conductivity, calcium and magnesium in both layers. Increased levels of nitrogen and potassium in the layer of $0.25-0.50 \mathrm{~m}$. Provided favorable conditions for absorption of some nutrients by plants. However further studies with higher doses and different cycles become necessary to have greater clarity about the behavior of the ARRA on the ground.
\end{abstract}

KEYWORDS: wastewater, environmental impact, reuse.

\section{INTRODUÇÃO}

A utilização de águas residuárias não é um conceito novo e há muito tempo tem sido praticado. No Brasil, há certa falta de tradição em relação à reciclagem de resíduos orgânicos. Todavia, nos últimos anos a aplicação de água residuária na agricultura tem recebido atenção considerável, ganhando importância devido à redução da disponibilidade de recursos hídricos de boa qualidade (CAOVILLA et al., 2010).

Dentre as vantagens do aproveitamento de água residuária pode-se citar a conservação das águas de boa qualidade, a grande disponibilidade de efluentes, a possibilidade do aporte e reciclagem de nutrientes (reduzindo a necessidade de fertilizantes químicos) e a preservação do meio ambiente (van der HOEK et al., 2002).

O Brasil é considerado o maior exportador e terceiro maior produtor mundial de carne de frango (ABPA, 2015), sendo que esta atividade vem ganhando grande destaque ao longo dos anos na economia brasileira. Por outro lado, gera problemas ambientais decorrentes da destinação inadequada das águas residuárias originadas durante o processamento do produto. A utilização agrícola deste resíduo se destaca, surgindo como alternativa para seu descarte, com o benefício do aproveitamento dos nutrientes para as culturas.

O efluente proveniente de abatedouros de aves pode ser aproveitado em solos agrícolas visando diminuir a utilização de fertilizantes químicos, porém deve 
ser utilizado de forma cautelosa para não promover alterações negativas nas propriedades químicas e físicas do solo (SILVA et al., 2007).

O conhecimento que possibilite a utilização das águas residuárias oriundas dos diversos processos produtivos em áreas agrícolas, reduzindo o impacto ambiental, reduzindo custos com fertilizantes químicos e aumentando a produtividade é de fundamental importância para os produtores nos dias atuais (TREVISAN et al., 2013).

Diante do exposto, este trabalho teve como objetivo avaliar os efeitos da aplicação de diferentes doses de água residuária de abatedouro de aves nas características químicas de um Latossolo Vermelho Distrófico cultivado com capim Mombaça (Panicum maximum cv. Mombaça).

\section{MATERIAL E MÉTODOS}

O experimento foi conduzido em ambiente protegido no Departamento de Engenharia Agrícola - DEA da Universidade Estadual de Maringá, no município de Cidade Gaúcha - PR, coordenadas 2321' 45" S e 52 $55^{\prime} 33^{\prime \prime}$ W e altitude de 345 m.

De acordo com a classificação do Köppen o clima da região é subtropical úmido mesotérmico, com verões quentes e tendências de concentrações de chuvas, temperatura anual média de $22^{\circ} \mathrm{C}$, invernos com geadas pouco frequentes e sem estação seca definida.

O delineamento experimental é inteiramente casualizado (DIC), em esquema de parcelas subdivididas com quatro repetições. Nas parcelas foram avaliadas cinco doses de água residuária de abatedouro de aves (0,150, 300, 600 e $\left.900 \mathrm{~m}^{3} \mathrm{ha}^{-1}\right)$ e na subparcela a concentração de alguns elementos químicos do solo em duas profundidades $(0,00-0,25$ e 0,25-0,50 m).

O solo utilizado foi classificado como Latossolo Vermelho Distrófico (EMBRAPA, 2013). Com composição granulométrica de $88 \%$ de areia, $1 \%$ de silte e $11 \%$ de argila na camada de $0,00-0,25 \mathrm{~m}$ de profundidade e $79 \%$ de areia, $2 \%$ de silte e $19 \%$ de argila na camada de 0,25-0,50 $\mathrm{m}$ de profundidade (PANINI et al., 2015). A Tabela 1 apresenta a caracterização química do solo anterior à aplicação de água residuária de abatedouro de aves (ARAA), de acordo com metodologias descritas em EMBRAPA (2009).

TABELA 1 Caracterização química do solo, por camadas, anterior à aplicação de ARAA.

\begin{tabular}{lccc} 
& & \multicolumn{2}{c}{ CAMADAS } \\
\cline { 3 - 4 } PARÂMETROS & UNIDADES & $\mathbf{0 , 0 0 - 0 , 2 5 m}$ & $\mathbf{0 , 2 5 - 0 , 5 0 m}$ \\
\hline $\mathrm{pH}$ & - & 5,62 & 5,85 \\
$\mathrm{CE}$ & $\mathrm{Ms} \mathrm{cm}^{-1}$ & 31,41 & 16,22 \\
$\mathrm{~N}$ & $\mathrm{mg} \mathrm{dm}^{-3}$ & 36,75 & 26,25 \\
$\mathrm{Ca}$ & $\mathrm{mg} \mathrm{dm}^{-3}$ & 1,12 & 0,91 \\
$\mathrm{Mg}$ & $\mathrm{mg} \mathrm{dm}^{-3}$ & 0,42 & 0,64 \\
$\mathrm{~K}$ & $\mathrm{mg} \mathrm{dm}^{-3}$ & 0,18 & 0,07 \\
$\mathrm{P}$ & $\mathrm{mg} \mathrm{dm}^{-3}$ & 4,03 & 2,91 \\
\hline
\end{tabular}

$\mathrm{pH}$ em $\mathrm{CaCl}_{2}$; $\mathrm{CE}$ (condutividade elétrica): medida com condutivímetro de bancada; $\mathrm{N}$ : método semi-micro Kjeldahl; Ca, Mg, K e P: Mehlich. Adaptado de LOZANO et al. (2015). 
A água residuária utilizada no presente estudo foi coletada no sistema de tratamento de uma indústria de abate de frango, localizada na região noroeste do Paraná, na qual ocorre o processamento de 35.000 aves dia ${ }^{-1}$. A coleta para análise química seguiu a metodologia estabelecida pela norma NBR 10.007 (ABNT, 2004). Os parâmetros nitrogênio $(N T K)$, fósforo $(P)$, potássio $(K)$, cálcio $(\mathrm{Ca})$, magnésio $(\mathrm{Mg})$, demanda bioquímica de oxigênio (DBO), demanda química de oxigênio (DQO), sólidos totais (ST) e sódio ( $\mathrm{Na}$ ) foram analisados de acordo com metodologias descritas em APHA et al. (1998), o pH e a condutividade elétrica (CE) foram determinados por meio de leitura direta, conforme apresentado na Tabela 2.

TABELA 2 Caracterização da água residuária de abatedouro de aves coletada na terceira lagoa de estabilização.

\begin{tabular}{ccc}
\hline PARÂMETRO & UNIDADE & VALOR \\
\hline NTK $^{*}$ & $\mathrm{mg} \mathrm{L}^{-1}$ & 26,25 \\
$\mathrm{P}$ & $\mathrm{mg} \mathrm{L}^{-1}$ & 0,80 \\
$\mathrm{~K}$ & $\mathrm{mg} \mathrm{L}^{-1}$ & 45,90 \\
$\mathrm{Ca}$ & $\mathrm{mg} \mathrm{L}^{-1}$ & 2,00 \\
$\mathrm{Mg}$ & $\mathrm{mg} \mathrm{L}^{-1}$ & 1,20 \\
DBO & $\mathrm{mg} \mathrm{L}^{-1}$ & 170,00 \\
DQO & $\mathrm{mg} \mathrm{L}^{-1}$ & 291,00 \\
pH & - & 8,18 \\
$\mathrm{CE}$ & $\mathrm{Ms} \mathrm{cm}^{-1}$ & 845,90 \\
$\mathrm{ST}$ & $\mathrm{mg} \mathrm{L}^{-1}$ & 704,43 \\
$\mathrm{Na}$ & $\mathrm{mg} \mathrm{L}^{-1}$ & 49,50 \\
\hline
\end{tabular}

* Nitrogênio pelo método NTK. Adaptado de LOZANO et al. (2015).

A área experimental foi constituída por 20 tubos de PVC de $0,10 \mathrm{~m}$ de diâmetro e 0,60 m de altura dispostos verticalmente, na base foram adaptadas telas de nylon (malha $1 \mathrm{~mm}$ ) e pratos de jardim perfurados para evitar perdas de solo. A deposição do solo nas colunas foi realizada após o solo ser seco ao ar livre por 60 horas e peneirado em peneira de malha de $2 \mathrm{~mm}$, sendo acondicionado de forma gradual, reproduzindo semelhantemente a condição do ambiente natural (LOZANO et al., 2015).

O capim mombaça foi semeado manualmente, no qual decorrido um período de 21 dias realizou-se um desbaste, deixando apenas três plantas em cada coluna de solo. A aplicação da água residuária foi realizada manualmente, com o auxílio de uma proveta graduada, no qual o tratamento testemunha $\left(T_{0}\right)$ recebeu somente água destilada, $T_{1}$ uma única aplicação de $150 \mathrm{~m}^{3} \mathrm{ha}^{-1}$ de ARAA e para os tratamentos $T_{2}$, $\mathrm{T}_{3}$ e $\mathrm{T}_{4}$ as doses foram fracionadas $\left(150 \mathrm{~m}^{3} \mathrm{ha}^{-1}\right)$ em intervalos de três dias até totalizar 300, 600 e $900 \mathrm{~m}^{3} \mathrm{ha}^{-1}$, respectivamente.

Para avaliação das possíveis alterações químicas que o solo sofreu com a aplicação da ARAA, foram retiradas após um período de 45 dias, amostras do solo nas duas camadas em estudo e realizado a análise química. Os parâmetros analisados foram $\mathrm{pH}, \mathrm{CE}, \mathrm{Ca}, \mathrm{Mg}, \mathrm{N}, \mathrm{P}$ e K.

Os resultados obtidos nas análises químicas do solo foram submetidos à análise de variância (ANOVA) ao nível de $5 \%$ de significância. Em relação aos 
fatores qualitativos que se mostraram significativos foi realizada comparação de médias por meio do teste Tukey e para os fatores quantitativos foi realizada a análise de regressão. Ambos os testes ao nível de $5 \%$ de probabilidade. Todas as análises foram realizadas empregando o programa SISVAR ${ }^{\circledR}$ (FERREIRA, 2014).

\section{RESULTADOS E DISCUSSÃO}

A análise de variância dos parâmetros estudados está apresentada na Tabela 3 , a qual demonstra que a interação entre as doses e as camadas não foi significativa pelo teste $\mathrm{F}$ ao nível de $5 \%$ em todas as variáveis, ou seja, os fatores atuam independentes. No entanto, houve significância em função da profundidade para as variáveis $\mathrm{pH}, \mathrm{CE}, \mathrm{Ca}, \mathrm{Mg}, \mathrm{N}, \mathrm{P}$ e K. Sendo possível observar também diferença significativa em função das doses de ARAA aplicadas para as variáveis $\mathrm{pH}, \mathrm{Ca}$ e Mg.

TABELA 3 Resumo da análise de variância para os resultados de pH e CE, dos teores de $\mathrm{Ca}, \mathrm{Mg}, \mathrm{N}, \mathrm{P}$ e K encontrados no solo após tratamento de água residuária de abatedouro de aves.

\begin{tabular}{|c|c|c|c|c|c|c|c|c|}
\hline \multirow{2}{*}{$\begin{array}{l}\text { Fonte de } \\
\text { variação }\end{array}$} & \multirow{2}{*}{ GL } & \multicolumn{7}{|c|}{ Valores calculados de F } \\
\hline & & $\mathrm{pH}$ & CE & $\mathrm{Ca}$ & Mg & $\mathbf{N}$ & $\mathbf{P}$ & K \\
\hline Doses $(A)$ & 4 & $0.0006^{*}$ & $0.3129^{\mathrm{NS}}$ & $0.0002^{*}$ & $0.0006^{*}$ & $0.2542^{N S}$ & $0.7257^{\mathrm{NS}}$ & $0.3654^{\mathrm{NS}}$ \\
\hline Profundidade (B) & 1 & $0.0050^{*}$ & $0.0035^{\star}$ & $0.0027^{\star}$ & $0.0072^{*}$ & $0.0435^{\star}$ & $0.0000^{*}$ & $0.0042^{*}$ \\
\hline$A^{*} B$ & 4 & $0.1572^{\mathrm{NS}}$ & $0.7670^{\mathrm{NS}}$ & $0.5580^{\mathrm{NS}}$ & $0.4597^{\mathrm{NS}}$ & $0.4964^{\mathrm{NS}}$ & $0.2088^{\mathrm{NS}}$ & $0.1089^{N S}$ \\
\hline CV 1 (\%) & & 2.57 & 40.04 & 22.51 & 7.56 & 27.09 & 46.57 & 46.37 \\
\hline CV $2(\%)$ & & 2.62 & 52.54 & 22.03 & 19.2 & 19.86 & 43.29 & 46.69 \\
\hline
\end{tabular}

Os valores de $\mathrm{pH}$ do solo foram influenciados pelas doses de água residuária de abatedouro de aves aplicadas, sendo possível ajustar um modelo de regressão quadrática, significativa a nível de 5\%, conforme apresentado na Figura 1.

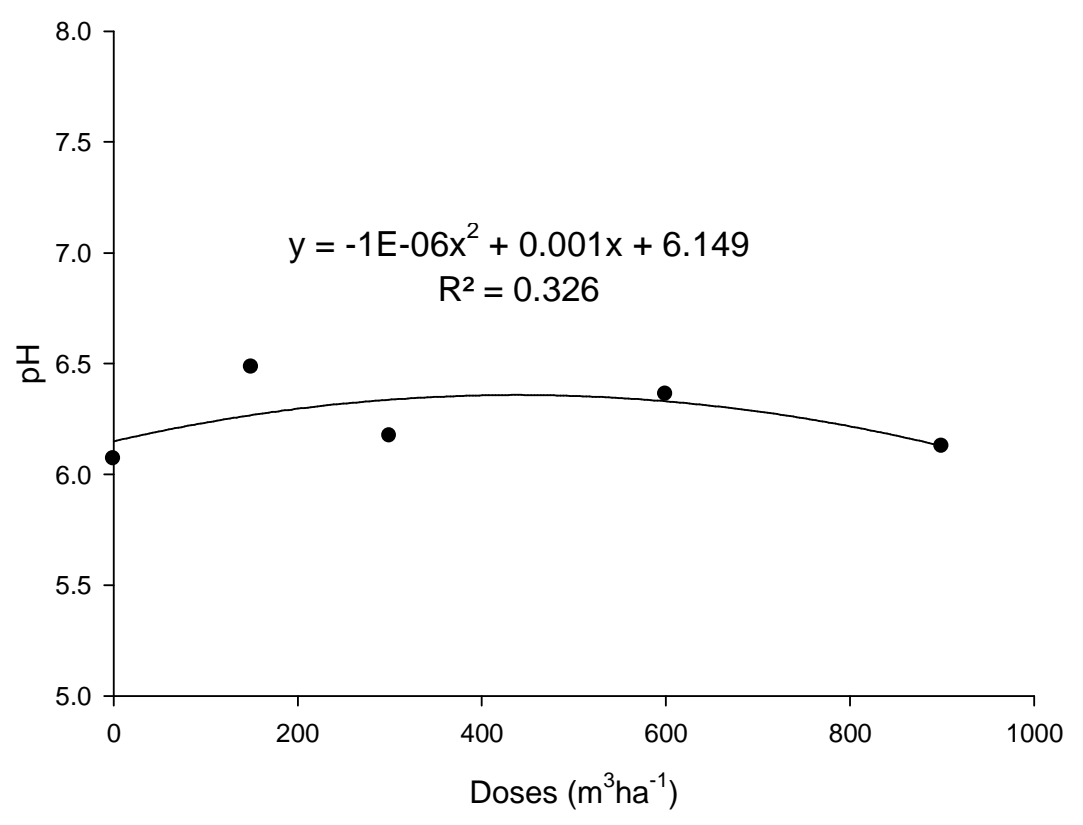

FIGURA 1. pH do solo em função das doses de ARAA. 
Os resultados mostraram que a aplicação de ARAA pode influenciar positivamente no $\mathrm{pH}$ do solo pelo fato da adição de ânions e cátions trocáveis. No entanto, CABRAL et al., (2011) ao aplicar água residuária de suinocultura no solo cultivado com capim elefante não verificaram diferença do $\mathrm{pH}$ do solo em função das diferentes doses aplicadas, divergindo dos resultados encontrados no presente estudo.

A Tabela 4 apresenta os valores médios de $\mathrm{pH}$ nas diferentes camadas após os ensaios realizados com água residuária de abatedouro de aves. Antes da aplicação da ARAA o solo apresentava pH 5,62 e 5,85, atingindo após aplicação valores médios de 6,15 e 6,32 nas camadas 0,00-0,25 e 0,25-0,50 m, respectivamente. Estes resultados indicam que houve elevação em ambas camadas ficando os valores de $\mathrm{pH}$, próximos da neutralidade.

TABELA 4 Valores médios de $\mathrm{pH}, \mathrm{CE}, \mathrm{Ca}, \mathrm{Mg}, \mathrm{N}, \mathrm{P}$ e $\mathrm{K}$ nas diferentes camadas, sob aplicação de água residuária de abatedouro de aves.

\begin{tabular}{|c|c|c|c|c|c|c|c|}
\hline $\begin{array}{c}\text { Profundidade } \\
(\mathrm{m})\end{array}$ & $\mathrm{pH}$ & $\begin{array}{c}\mathrm{CE} \\
\left(\mu \mathrm{cm}^{-1}\right)\end{array}$ & $\underset{\left(\mathrm{mg} \mathrm{dm}^{-3}\right)}{\mathrm{Ca}}$ & $\underset{\left(\mathrm{mg} \mathrm{dm}^{-3}\right)}{\mathbf{M g}}$ & $\begin{array}{c}\mathbf{N} \\
\left(\mathbf{m g ~ d m}^{-3}\right)\end{array}$ & $\begin{array}{c}\mathbf{P} \\
\left(\mathrm{mg} \mathrm{dm}^{-3}\right)\end{array}$ & $\begin{array}{c}\mathrm{K} \\
\left(\mathrm{mg} \mathrm{dm}^{-3}\right)\end{array}$ \\
\hline $0,00-0,25$ & $6,158 \mathbf{b}$ & $15,009 \mathbf{a}$ & $0,984 \mathbf{a}$ & $0,403 \mathbf{b}$ & $31,762 \mathbf{b}$ & $7,658 \mathbf{a}$ & $0,075 \mathbf{b}$ \\
\hline $0,25-0,50$ & $6,328 \mathbf{a}$ & $8,308 \mathbf{b}$ & $0,765 \mathbf{b}$ & $0,487 \mathbf{a}$ & $36,487 \mathbf{a}$ & $2,589 \mathbf{b}$ & $0,125 \mathbf{a}$ \\
\hline
\end{tabular}

${ }^{*}$ Médias seguidas da mesma letra na coluna não apresentam diferença significativa pelo teste de Tukey ao nível de $5 \%$ de probabilidade.

Em relação ao comportamento do $\mathrm{pH}$ no perfil do solo é possível verificar redução da acidez com o aumento da profundidade (Tabela 4). Esse resultado corrobora com os encontrados por MEDEIROS et al. (2011) ao aplicarem água residuária de suinocultura no solo.

A maior concentração de raízes da gramínea na camada superficial pode ser a possível explicação para este comportamento de $\mathrm{pH}$. A própria absorção de nutrientes pelas raízes das plantas gera um ambiente ácido na zona da rizosfera, uma vez que, ao absorver os cátions as raízes liberam um íon hidrogênio $\left(\mathrm{H}^{+}\right)$para o meio (PRADO, 2008).

$\mathrm{O} \mathrm{pH}$ é um importante indicador das condições química do solo, pois tem a capacidade de influenciar na disponibilidade de nutrientes às plantas, podendo atuar positiva ou negativamente sobre a disponibilidade dos elementos químicos necessários às plantas (BRANDÃO \& LIMA, 2002; PRADO, 2008; VAN RAIJ, 2011).

A condutividade elétrica (CE) na camada de solo de 0,00-0,25 supera e difere da camada de 0,25-0,50, conforme apresentado na Tabela 4. Este comportamento da CE provavelmente foi mais influenciado pelos valores iniciais de CE, antes da aplicação da ARAA, nas duas camadas (Tabela 1) do que pela ação das doses propriamente dita. Com relação a esta característica relacionada à salinização é possível observar que houve redução da CE do solo após a aplicação de água residuária de abatedouro de aves. O comportamento dos valores de cálcio $(\mathrm{Ca})$ no solo com aplicação de ARAA está apresentado na Figura 2. 


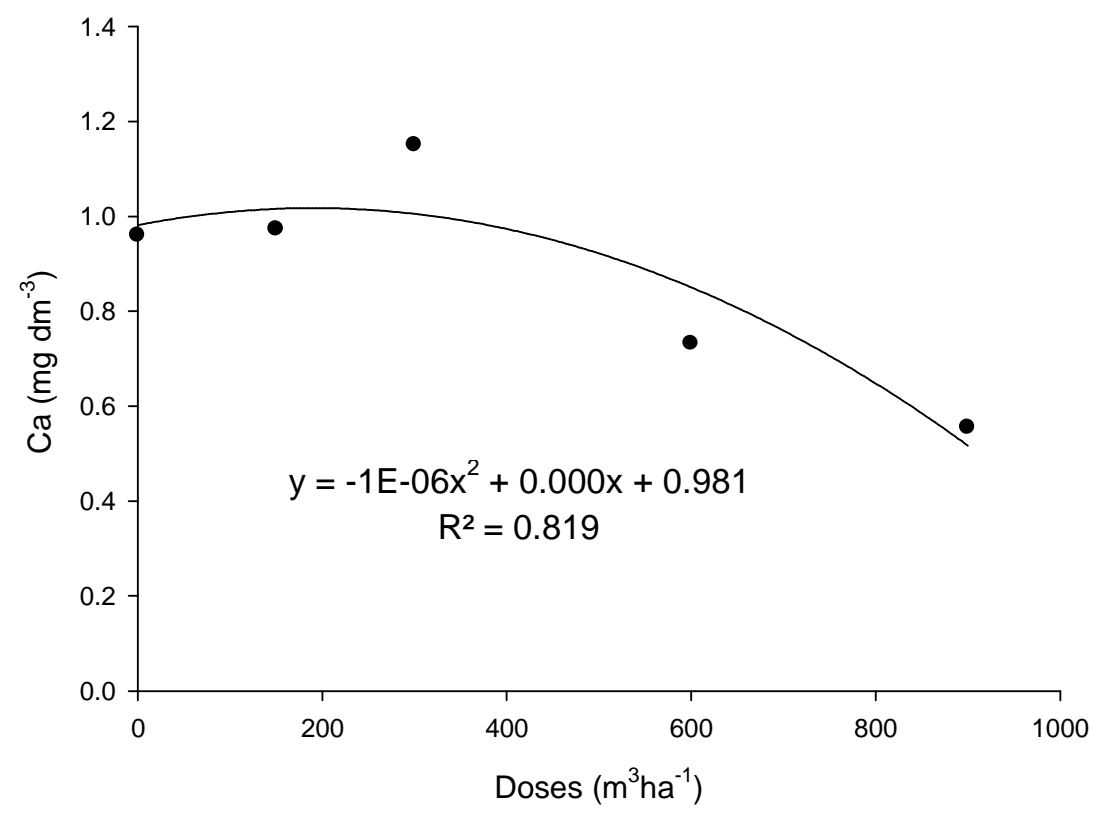

FIGURA 2. Teores de Ca em função das doses de ARAA.

Verifica-se que a aplicação da água residuária de abatedouro de aves promoveu elevação da concentração de Ca até a dose de $300 \mathrm{~m}^{3} \mathrm{ha} \mathrm{C}^{-1}$ e a partir desta dose passou a sofrer decréscimo. Possivelmente este comportamento ocorreu devido ao fato de que às plantas da gramínea forrageira utilizada nesse estudo apresentar visualmente maior desenvolvimento da parte aérea e das raízes nos tratamentos que receberam as maiores doses, fazendo com que as plantas tivessem que absorver mais $\mathrm{Ca}$.

De acordo com PRADO (2008) o Ca possui como principal função atuar na estrutura da planta como componente da parede celular. Sendo a parede celular quantitativamente o maior "produto" das plantas, quanto maior seu desenvolvimento maior será a necessidade de Ca.

Observa-se que a concentração de Ca na camada de solo de 0,00-0,25 m supera e difere da camada de 0,25-0,50 m (Tabela 4). Antes da aplicação de ARAA e do plantio da gramínea, a concentração de Ca encontrada no solo era de 1,12 e $0,91 \mathrm{mg} \mathrm{dm}^{-3}$ nas camadas de 0,00-25 e 0,25-0,50 m respectivamente e após a aplicação esses valores de Ca reduziram em ambas as camadas. Estes resultados corroboram com os encontrados por TREVISAN et al., (2013) que verificaram redução nos teores de Ca após a aplicação de água residuária de suinocultura em colunas de solo preenchidas com Nitossolo Vermelho Distroférrico.

$\mathrm{Na}$ Figura 3 observa-se que as menores concentrações de magnésio $(\mathrm{Mg})$ no solo foram encontradas nos tratamentos que receberam maiores doses de água residuária de abatedouro de aves. O modelo de regressão ajustado as concentrações de Mg no solo foi linear decrescente, significativa a 5\%. 


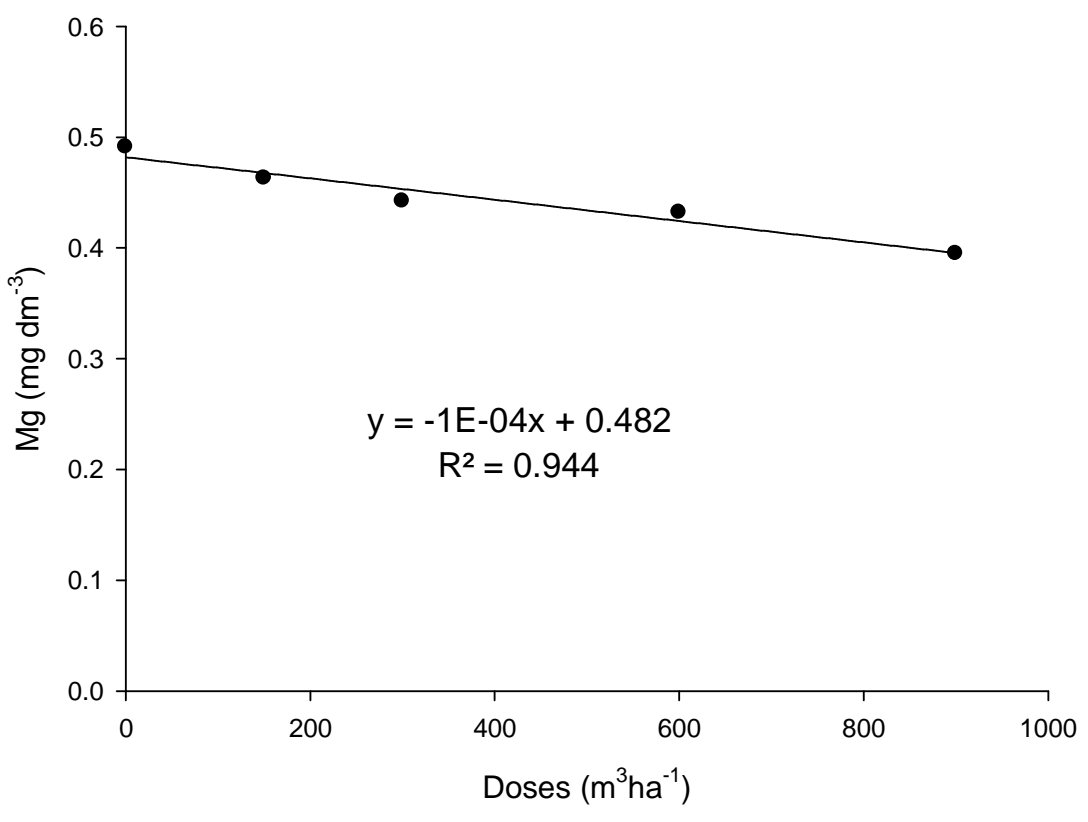

FIGURA 3. Teores de Mg em função das doses de ARAA.

Estes resultados verificados estão relacionados provavelmente devido a maior absorção de Mg pelas plantas nos tratamentos com doses maiores, no qual foi possível observar visualmente acréscimo na produção.

Nota-se na Tabela 4 que na camada de $0,00-0,25 \mathrm{~m}$ a concentração de $\mathrm{Mg}$ foi inferior, diferindo da camada de 0,25-0,50 m. Resultados diferentes foram observados por CABRAL et al., (2011) na qual os maiores valores de Mg foram encontrados na camada superficial após a aplicação de água residuária de suinocultura.

O nitrogênio $(\mathrm{N})$ na camada de 0,00-0,25 é menor e difere da concentração média encontrada na camada de 0,25-0,50 m (Tabela 4). O valor inicial de $\mathrm{N}$ no solo, antes da aplicação da ARAA e do plantio do capim Mombaça, na camada de $0,25-0,50 \mathrm{~m}$ era de $26,25 \mathrm{mg} \mathrm{dm}^{-3}$ sendo possível verificar acréscimo após aplicação da ARAA, passando para $36,48 \mathrm{mg} \mathrm{dm}^{-3}$. Esse nutriente pode ter se translocado para a camada inferior, e por isso o aumento na camada de 0,25-0,50 m de profundidade. Uma possível explicação para os menores valores na camada superior é que as plantas podem ter absorvido mais este elemento nesta camada. Segundo PRADO (2008), o N é o elemento macronutriente mais extraído pelas plantas cultivadas.

Observa-se que a concentração de fósforo $(P)$ na camada de solo de 0,000,25 supera e difere da camada de 0,25-0,50 m (Tabela 4). A elevação do pH proporciona maior disponibilidade deste elemento. Valores de $\mathrm{pH}$ do solo iguais ou pouco superiores à 6,00 favorecem a maior disponibilização de $\mathrm{P}$ (van RAIJ, 2011).

A concentração inicial média de $P$ no solo era de 4,03 e 2,91 passando para 7,65 e 2,85 nas camadas de 0,00-0,25 e 0,25-0,50 m, respectivamente, após a aplicação de água residuária de abatedouro de aves (Tabela 4). Apesar da aplicação da ARAA não se verificou aumento nos teores de $P$ na camada 0,25-0,50m. Este comportamento é justificado pelo fato deste elemento possuir baixa mobilidade em solos oriundo de regiões tropicais onde predominam minerais de argila do tipo 1:1 
(caulinita) e óxidos de ferro $\left(\mathrm{Fe}_{2} \mathrm{O}_{3}\right)$, alumínio $\left(\mathrm{Al}_{2} \mathrm{O}_{3}\right)$, manganês $\left(\mathrm{Mn}_{2} \mathrm{O}_{3}\right)$ e titânio $\left(\mathrm{TiO}_{2}\right)$ (BRADY \& WEIL, 2013; MEURER, 2012).

$\mathrm{O} P$ é exigido pelas plantas em menor quantidade do que o potássio e o nitrogênio, no entanto as perdas de $P$ por lixiviação são pequenas, sendo facilmente fixados no solo tornando-se insolúveis e indisponíveis para as plantas (van RAIJ, 2011).

Resultados semelhantes foram encontrados por CABRAL et al., (2011) ao aplicar água residuária de suinocultura no solo cultivado com capim-elefante, no qual a camada superficial superou e diferiu das demais camadas. $\mathrm{O}$ teor de potássio $(\mathrm{K})$ do efluente $\left(45,90 \mathrm{mg} \mathrm{L}^{-1}\right.$ ) auxiliou no suprimento desse elemento, uma vez que esse nutriente é exigido em grandes quantidades pelas plantas. No início do experimento foram observados $0,18 \mathrm{mg} \mathrm{dm}^{-3}$ e $0,07 \mathrm{mg} \mathrm{dm}^{-3}$ de $\mathrm{K}$ nas camadas $0,00-0,25$ e 0,25$0,50 \mathrm{~m}$, respectivamente (Tabela 1 ).

Nota-se que na camada superior o teor de $\mathrm{K}$ foi menor $\left(0,075 \mathrm{mg} \mathrm{dm}^{-3}\right)$ que na camada inferior $\left(0,125 \mathrm{mg} \mathrm{dm}^{-3}\right)$ - (Tabela 4). A menor concentração de $\mathrm{K}$ na camada $0,00-0,25 \mathrm{~m}$ pode ter ocorrido devido à movimentação desse elemento no solo, promovendo aumento na camada $0,25-0,50 \mathrm{~m}$ e também pela absorção pelas plantas. PRADO (2008) relata que o K é um dos elementos macronutrientes primários de grande mobilidade no solo, por isso, facilmente translocado e perdido por lixiviação no solo.

$\mathrm{O}$ acúmulo de $\mathrm{K}$ devido à aplicação constante e por períodos longos de resíduos industriais pode provocar efeito salino na camada superficial e sua lixiviação acarretar contaminação das águas subterrâneas.

No caso do presente estudo, é possível que isto não tenha ocorrido porque as doses aplicadas não são consideradas elevadas e também porque a planta cultivada (Mombaça) auxiliou na absorção deste elemento. Porém para doses maiores e para períodos de aplicação constantes ao longo de vários ciclos de culturas ou vários anos, é possível que ocorram problemas. Neste sentido, novos estudos com maiores doses e diversos ciclos tornam-se necessários para se ter maior clareza sobre o comportamento da ARAA no solo.

\section{CONCLUSÃO}

A água residuária de abatedouro de aves contribuiu para o aumento do $\mathrm{pH}$ do solo em ambas as camadas.

A redução da $\mathrm{CE}, \mathrm{Ca}$ e $\mathrm{Mg}$ em ambas as camadas avaliadas após aplicação de ARAA ocorreu em função do efeito da planta sobre estes parâmetros.

Houve o aumento dos teores de $\mathrm{N}$ e $\mathrm{K}$ na camada de 0,25-0,50 m de profundidade.

A aplicação do resíduo líquido de abatedouro de aves, nas doses avaliadas, além de fornecer nutrientes, proporcionou melhores condições de $\mathrm{pH}$, favorecendo a absorção de alguns nutrientes pelas plantas.

\section{REFERÊNCIAS}

ABNT - ASSOCIAÇÃO BRASILEIRA DE NORMAS TÉCNICAS. NBR 10007. Amostragem de resíduos: Classificação, Rio de Janeiro, 2004. 21 p.

ABPA - ASSOCIAÇÃO BRASILEIRA DE PROTEÍNA ANIMAL. Relatório anual de 2015. São Paulo, 2015, 245p. 
APHA; AWWA; WEF. Standard methods for examination of water and wastewater, 20th Ed. Washington D.C, 1998.

BRADY, N. C.; WEIL, R. R. Elementos da natureza e propriedades do solo. 3. ed. Porto Alegre: Bookman, 2013. 686 p.

BRANDÃO, S.L.; LIMA, S.C. pH e condutividade elétrica em solução do solo, em áreas de pinus e cerrado na chapada, em Uberlândia (MG). Caminhos de geografia, v.3, n.6, p.46-56, 2002.

CABRAL, J. R.; FREITAS, P.S.L; REZENDE,R.; MUNIZ, A.S.; BERTONHA, A. Impacto da água residuária de suinocultura no solo e na produção de capimelefante. Revista Brasileira de Engenharia Agrícola e Ambiental, Campina Grande, v.15, n.8, p.823-831, 2011. Disponível em: < http://www.scielo.br/scielo.php?script=sci_arttext\&pid=S1415-43662011000800009>. doi: dx.doi.org/10.1590/S1415-43662011000800009

CAOVILLA, F.A.; SAMPAIO, S.C.; SMANHOTTO,A.; NÓBREGA,L.H.P.; QUEIROZ,M.M.F.; GOMES, B.M. Características químicas de solo cultivado com soja e irrgado com água residuária da suinocultura. Revista Brasileira de Engenharia Agrícola e Ambiental, Campina Grande, v.14, n.7, p.692-697, 2010. Disponível em: < http://www.scielo.br/scielo.php?script=sci_arttext\&pid=S141543662010000700002>. doi: dx.doi.org/10.1590/S1415-43662010000700002

EMBRAPA - EMPRESA BRASILEIRA DE PESQUISA AGROPECUÁRIA. Manual de análises químicas de solos, plantas e fertilizantes. 2.ed. Brasília: Embrapa Informação Tecnológica, 2009. 627 p.

EMBRAPA - EMPRESA BRASILEIRA DE PESQUISA AGROPECUÁRIA. Centro Nacional de Pesquisa de Solos. Sistema brasileiro de classificação de solos. 3.ed., Rio de Janeiro: Embrapa Solos, 2013, 353 p.

FERREIRA, D. F. Sisvar: a Guide for its Bootstrap procedures in multiple comparisons. Ciência eCIS Agrotecnologia (UFLA), v. 38, n.2, p. 109-112, 2014. Disponível em: <HTTP://www.scielo.br/scielo.php?script=sci_arttext\&pid=S141370542014000200001\&lng=es\&nrm=iso>. doi: dx.doi.org/10.1590/s141370542014000200001

LOZANO, C. S.; TONELlO, T. U.; BORTOLETTO, E. C.; ARAUJO, M. A.; TONELLO, A. P. Resposta do capim Mombaça (Panicum maximum cv. Mombaça) submetido à aplicação de água residuária de abatedouro de aves. Enciclopédia Biosfera, v. 11, n. 22, p. 3796-3805, 2015. Disponível em: http://www.conhecer.org.br/enciclop/2015c/agrarias/resposta\%20do\%20capim.pdf. doi: http://dx.doi.org/10.18677/Enciclopedia_Biosfera_2015_267

MEDEIROS, S. S.; GHEYI, H. R.; PÉREZ-MARIN, A. M.; SOARES, F. A. L.; FERNANDES, D. Características químicas do solo sob algodoeiro em área que recebeu água residuária da suinocultura. Revista Brasileira de Ciência do Solo, v. 35, p.1047-1055, 2011. Disponível em: < http://www.scielo.br/scielo.php?pid=S0100- 
06832011000300038\&script=sci_abstract\&tlng=pt>. doi: dx.doi.org/10.1590/S010006832011000300038

MEURER, E. J. Fundamentos de química do solo. 5 ed. Porto Alegre: Evangraf, 2012, $280 \mathrm{p}$.

PANINI, R. L.; ARAUJO, M. A; BERTOLDI, I. R; MORAES JÚNIOR, J. C; USHIWATA, S. Y; SOUZA, S. L. Levantamento de uso atual e classificação dos solos do campus do arenito em Cidade Gaúcha - PR. In: IX Encontro Internacional de Produção Científica UniCesumar - IX EPCC, 2015. Editora UniCesumar, Maringá - PR. 2015. Anais Eletrônico.

PRADO, R. M.; Nutrição de plantas. Editora UNESP, São Paulo - SP, 2008. 407p.

SILVA, M.A.S; GRIEBELER, N.P; BORGES, L.C. Uso de vinhaça e impactos nas propriedades do solo e lençol freático. Revista Brasileira de Engenharia Agrícola e Ambiental, Campina Grande, v.11, n.1, p.108-114, 2007. Disponível em: < http://www.scielo.br/pdf/rbeaa/v11n1/v11n1a14>. doi: dx.doi.org/10.1590/S141543662007000100014

TREVISAN, A. P.; FREITAS, P. S. L. REZENDE, R. SILVANO, C. FARIA JUNIOR, C.A. Atributos químicos do solo e qualidade do percolado com aplicação de água residuária de suinocultura. Enciclopédia Biosfera, v.9, n.16, p. 2686-2697, 2013.

VAN DER HOEK, W.; HASSAN, U. M.; ENSINK, J. H. J.; FEENSTRA, S.; RASCHIDSALLY, L.; MUNIR, S.; ASLAM, R.; ALIM, N.; HUSSAIN, R.; MATSUNO, Y. Urban Wastewater: A valuable resoure for agriculture. a case study from horoonabad, Pakistan. Research Report 63. Colombo, Sri Lanka: International Water Management Institute. 2002. 20p.

VAN RAIJ, B. Fertilidade do solo e manejo de nutrientes. Piracicaba: International Plant Nutrition Institute, 2011. 420 p. 